\title{
RETRACTED ARTICLE: Function finding for indirect determination of rock brittleness based on genetic programming and non-linear multiple regression models
}

\author{
Manoj Khandelwal ${ }^{1}$ (D) Roohollah Shirani Faradonbeh ${ }^{2}$ - Danial Jahed Armaghani ${ }^{3}$ \\ Muhd Zaimi Bin Abd Majid ${ }^{4}$ Masoud Monjezi ${ }^{5}$
}

Received: 7 December 2015 / Accepted: 17 February 2016 / Published online: 27 February 2016

(C) Springer-Verlag London 2016

Following the request of the corresponding author this article has been retracted as a result of a data set being used without permission. The online version of this article contains the full text of the retracted article as electronic supplementary material.

Electronic supplementary material The online version of this article (doi:10.1007/s00366-016-0441-6) contains the full text of the retracted article as electronic supplementary material.

\section{Manoj Khandelwal}

m.khandelwal@federation.edu.au;

mkhandelwal1@gmail.com

Roohollah Shirani Faradonbeh

Roohollah.Shirani@modares.ac.ir

Danial Jahed Armaghani

danialarmaghani@gmail.com

Muhd Zaimi Bin Abd Majid

mzaimi@utm.my

Masoud Monjezi

monjezi@modares.ac.ir
Faculty of Science and Technology, Federation University Australia, PO Box 663, Ballarat, VIC 3353, Australia

2 Young Researchers and Elite Club, South Tehran Branch, Islamic Azad University, Tehran, Iran

3 Department of Geotechnics and Transportation, Faculty of Civil Engineering, Universiti Teknologi Malaysia (UTM), 81310 Skudai, Johor, Malaysia

4 Construction Research Centre, Institute for Smart Infrastructure and Innovative Construction (ISIIC), Universiti Teknologi Malaysia (UTM), 81310 Skudai, Johor, Malaysia

5 Department of Mining, Faculty of Engineering, Tarbiat Modares University, Tehran 14115-143, Iran 